\title{
Study on the Role of Recitation Art on Vocal Singing
}

\author{
Jiani Feng \\ Shaanxi Xueqian Normal University, Xi’an, Shaanxi, 710000
}

Keywords: recitation art; vocal singing; application

\begin{abstract}
Recitation art is a kind of advanced vocal language art. It is a kind of language art that expresses the thoughts and feelings of works with beautiful language, clear pronunciation and rich tone. Vocal music is the oldest form of music. It is one of the carriers that express emotion and communicate with each other in production labor and social life. Recitation of art and vocal music is an art of teasing. Its purpose is to express the meaning of the expression and to resonate with the audience. The two have similarities and can learn from each other, especially in the practice of vocal singing, using some of the recitation techniques and Elemental training can improve the level of the singer.
\end{abstract}

\section{Introduction}

Vocal music is a kind of cultural art that expresses people's thoughts and emotions and reflects people's thoughts and emotions by combining language and music. The recitation art is the expression form of language, and the recitation art gives the singing language rich colors. Recitation is an emotional combination of word harmony. For ordinary people, recitation is a means of narrative and romance. If it appears on the stage of art, it will be sublimated into an expression of art. The requirements will have certain aesthetic value with others. The value is reflected in the performance ability of the readers, and the reading requirements for the readers in the face of the audience are focused on the need to have full emotions, loud voices, calm atmosphere, standard pronunciation, Clear words and accurate emotions, which just resonate with vocal singing, sing a good work, recitation is the premise and foundation, on the basis of reading, to understand and grasp the thoughts and emotions expressed in the works, to achieve the same feelings, It is considered to be a good vocal work, so recitation plays an important role in vocal singing. I hope that the singer can recognize the importance of recitation in singing, so that the skill can be developed to make the expression of emotion more expressive.

\section{The Impact of Recitation Art on Basic Skills of Singing}

The breath in the process of reciting, that is, breathing when reading a performance, in the simple and simple recitation situation, the breath of reading is simpler, and the breathing used in the singing of vocal songs is more strict on the basis of reading. Abdominal "combined breathing method is to use a steady breathing to prevent suffocation or lack of gas in the singing. During the performance, the muscles of the mouth and the muscles of the throat are slightly dilated and stretched slightly. When the recitation is performed, the oral muscles are pulled. It's not too big to exaggerate, but when singing, singing actors need to sing in love. When emotions need to be exaggerated, the oral muscles must be stretched to complete the vocal performance. Stretching is a process of exaggeration and expansion on the basis of recitation. Practice these is a great help to vocal singing. Our simplest and most effective method is to recite. In the professional reading and vocal singing, the chest-abdominal combined breathing method is a relatively recognized, natural and scientific breathing method. In the process of breathing, you can feel the breath is very full, the waist and abdomen have a feeling of rising, the diaphragm is very There is power, which means that the breath is very good. In the process of vocalization, there will be no shortage of breath. This method of breathing can be practiced in the reading and can be perfectly used in vocal singing. This is the reading of vocal music. Singing has a great help, and it is often practiced repeatedly in the 
readings. The integration is in the process of singing, and the practice of singing basic skills is greatly improved. Especially for beginners who have vocal music, there will be mistakes in the singing atmosphere. For example, the breath is too shallow, the suction is not deep, and when the singing is not enough, it will be suffocating, causing the singing to feel dizzy for a while. This is caused by the lack of breath. Oxygen deficiency, the essence of these problems is not the lack of breath, but the lack of skills, blind inhalation, irregular ventilation, to solve these problems must first be resolved in the concept, the concept of recognizing the practice in the recitation, step by step, slowly Finding the essentials of weapons, after long-term training, it will become a platform for vocal music. After practicing and applying it to singing, it will be natural and comfortable. By practicing the breath by the recitation method, the vocal performer can be psychologically relaxed and free, and can quickly achieve a smooth atmosphere and smooth application. Therefore, in normal times, you should feel more and experience the state of loud reading, apply this state to singing, and sing with the same feeling.

\section{Recitation of Emotional Expression of Songs}

In order to get a pleasant and pleasant voice, we must master the methods and techniques of scientific and natural vocalization. First of all, we must have a correct circle of words, and have a head and tail. We must also display different sound characteristics according to the emotions of the works, showing the rhythm of the song itself. The beauty of the text and the beauty of the mood. For example, "Wen Xin Diao Long. Voice" said, "The sound turns to kiss, Lingling is like Zhenyu, reciting in the ear, tired like a bead." Su Shi's "Xijiang Yue" Cloud: "Flowers and smog drifting, the songs are dripping and clear." People listened to their hearts and minds, and the long-term beauty. Recitation is the most effective way to help the singer accurately grasp the thoughts, emotions and sound characteristics of the works. The emotions and role positions are the basis of singing. For example, there is no love for beauty, no hatred for ugliness, no sorrow for discrete bleakness. Whether it is poetry reading or song singing, it will not be touching and will not resonate with the audience. Recitation of this form of performance allows us to feel the depth of the work. In addition, the sense of language can enhance the sense of singing. The sense of music is straightforward and can be understood as the perception of music melody, rhythm, strength and emotion. It is also a scientific, real and professional emotional expression process. The sense of language promotes the development of music sense, and determines the target of music sense. The mutual music sense enhances the expressive ability of language sense. Therefore, the sense of language and the sense of music are organic unity, which lays the foundation for the emotional bursting of singing performances. The sense of language drives the sense of music. The sense of language transforms the unchanging words through the readings of the readers' language, and writes the written language. Transform into a creative process of a voice that speaks more emotionally. Recitation is the art of the expression of voiced language as its main means of expression, but it is not a general, simple way to turn a written language into a voiced language, but to give the information and emotions conveyed by the words. Singing is a musical instrument, combined with scientific vocal methods, correct singing skills and breathing methods, sensitive musical hearing and powerful rhythm to convey the content and emotions of the song, and ultimately achieve an artistic expression that expresses emotions and infects the audience. Techniques. As far as singing itself is concerned, it is a combination of language and music to convey thoughts and feelings and express artistic image. Language is the core and foundation of the expression and creation of sound art. The expression of any sound art cannot be separated from the language. In the voiced expression, the same point of reading and singing is the essence of the language through the expression of the language. Any vocal music school in the world is based on its own language. No matter how you use it, the sound should always be closely integrated with the language. The American Acoustics School emphasizes the importance of language accuracy to the singer. The Italian American Acoustics School has a famous saying, "Whoever speaks (reciting), whoever can sing (sing well). Chinese traditional vocal music includes drama, rap, folk singing. It is based on the "word-based" principle, and often combines with the white language when training the sound. 


\section{Improve the Method and Level of Vocal Singing by Recitation}

Before the vocal performance, emotionally recitation of the work not only enables the singer to familiarize and understand the song well, but also makes the complex vocal singing process concrete and visual. I am emotionally recitation of the work, mastering the elements of biting, voicing, breath, resonance, etc. in the reading, transplanting it into singing, making the vocalist's pronunciation clearer, more natural and singing a beautiful voice, thus further enhancing the singer science The vocal method and artistic processing ability. First of all, recitation works are conducive to improving the clarity of vocal and voicing in vocal performances and accurately expressing the connotation of the works. Wei Liangfu, a drama innovator of the Ming Dynasty in China, once said: "There are three songs in the song, the word is clear, the chamber is purely two, and the board is three." This shows the importance of the wording in vocal singing. Recitation and singing are all based on language. Reading is the basis of singing. Singing is a melodic melody. Compared with vocal singing, recitation is easier to make accurate words and clear words. In vocal performances, the lyrics are affected by factors such as melody, rhythm, pitch, etc., and it is inevitable that there will be problems with unclear words, and sometimes even ignore some words. Therefore, before the singing, performing recited exercises, exercising vocal organs, exercising the ability to sing and sing, and familiarizing with the connotation of the works, is conducive to improving the clarity of vocal and voicing in vocal performances, so that the singer can accurately grasp the tone of the law. The language that is spoken more naturally is more exaggerated, but the charm is very close to the singing state. Therefore, using the recitation method to exercise singing can enable the singer to accurately grasp the connotation of the work and regulate and express the song content.

Secondly, recitation works are good for exercising correct singing and breathing methods. Breathing is the basis and motivation of singing. There is such a record in ancient Chinese music theory: "A good singer must first adjust his temper and a pneumatic sound." The famous Italian singer Caruso also said: "A singing Whether or not he can embark on the road to success depends on whether his manipulation and control of the respiratory organs establish a strong foundation." Some beginners see the mystery of breathing in the mystery, coupled with the lack of correct sound concepts. And the scientific training method, not sucking more or sucking, eventually causing the tongue to be tight, the throat, the breath can not sink, and so on. In fact, the breathing state in singing and the breathing in the reading are consistent in physiological relationship. The difference is that the breathing in singing needs to be deeper, and it needs to be sucked fast, sucked deeply, and sucked softly and lightly. Compared with singing, there is no melody requirement, no treble requirements, no complicated mouth, emotional recital helps the singing atmosphere, and it is good for exercising correct singing and breathing methods. The singer is in vocal music. In the study, I use the feeling of reading to sing, to understand the use of breath and the expression of emotions, it is easier to grasp the correct breathing and vocal state.

\section{Conclusion}

There are many similarities between recitation art and vocal singing. Singing and recitation are all expressing thoughts and feelings through the words formed by sounds. Recitation is a natural way to practice first and then difficult, step by step, and have certain assistance to singing. effect. Through emotional reciting, the singer can establish a correct vocal state, better grasp the profound connotation of the work, master the style and characteristics of the work, standardize and express the song content, and form a good singing state.

\section{References}

[1] $\mathrm{Xu}$ Dagong. The Expression of Emotional Factors in Vocal Music Singing [J]. Platform, 2013(2):39-40.

[2] Qiu Jingjing. On the Emotional Expression in Vocal Music Singing [J]. Platform, 2014(9):138-139. 
[3] Huang Wenjie. Analysis of the Emotional Expression of Singing in Vocal Music Teaching [J]. Journal of Jimei University (Educational Science Edition), 2006(2): 81-84.

[4] Wei Pingnan, Wang Yiren. Appreciation of Sound and Sounds--On Emotional Expression in Vocal Music Singing [J]. Popular Literature, 2010(12): 23-24. 